\title{
A New Press Pack IGBT for High Reliable Applications With Short Circuit Failure Mode
}

\author{
Heng WANG, Jens PRZYBILLA, Hao ZHANG, and Juergen SCHIELE
}

\begin{abstract}
The modular multilevel converter (MMC or M2C) technology becomes the mainstream solution in today's voltage source converter-high voltage direct current (VSC-HVDC) transmission lines because of its unique performance. Recently press pack IGBT (PPI) has come into focus as a preferred realization for high power rating VSC-HVDC stations, it could offer the highest current rating IGBTs and advanced features in reliability. A new PPI is introduced in this paper, which is designed for several innovative improvements based on the application demands from VSC-HVDC systems. The chip is optimized for low on-state voltage with advanced trench technology, and well protected in a chip-stack by double side sinter process. The disc package is designed with hermetic sealed ceramic housing to avoid environmental erosion and could provide a robust feature of short circuit failure mode (SCFM), which is fully qualified under the worst-case scenario. In addition to the PPI device, system solutions had also been developed and investigated to support field developments, including electrical and mechanical design. An example of a power stack is analyzed in commutation loop, pressure distribution, and power losses.
\end{abstract}

Index Terms - Freewheeling diode (FWD), housing, lifetime, modular multilevel converter (MMC), press pack IGBT (PPI), short circuit failure mode (SCFM), thermal, VSC-HVDC.

\section{INTRODUCTION}

$\mathrm{H}$ VDC has been an alternative method of transmitting electric power from one location to another with some inherent advantages over AC transmission systems, like lower losses and decoupling of networks for different frequencies or phase shift. The efficiency and rated power carrying capacity of direct current transmission lines highly depend on the converter used in transforming the current from one form to another (AC to $\mathrm{DC}$ and vice versa). A well-configured converter reduces harmonics, increases power transfer capabilities and reliability by offering high tolerance to fault along the line. Different

Manuscript received February 27, 2021; revised April 27, 2021; accepted May 15, 2021. Date of publication June 30, 2021; date of current version June 17,2021 . This paper was presented in part at the 4th International Conference on HVDC (HVDC 2020), Xi'an, China, September 2020. (Corresponding author: Heng Wang.)

H. Wang and H. Zhang are with the Department of Industry Power Control of Infineon, Beijing and Shanghai office respectively, China (e-mail: Heng.Wang@, infineon.com; Hao.Zhang@infineon.com).

J. Przybilla and J. Schiele are with the Department of Infineon Technologies Bipolar GmbH \& Co. KG, Warstein, 59581, Germany (e-mail: Jens.Przybilla@) infineon-bip.com; Juergen.Schiele@infineon-bip.com).

Digital Object Identifier 10.24295/CPSSTPEA.2021.00009
HVDC converter topologies have been proposed, built, and utilized all over the world. The two dominant types however are the line commutated converter (LCC) and the voltage source converter (VSC).

\section{A. Voltage Source Converters}

The first HVDC installation using modular multilevel converter (MMC or M2C) topology was commissioned in 2010[1]. Since then, this topology evolved as a kind of standard for VSC-HVDC systems because of its advantages like black start capability, operation without filter, the low switching frequency of IGBT, easy modular setup and several other unique features [2].

The MMC consists of identical submodules in series connection, and standard industrial IGBT modules are used in most cases. The main topologies for these submodules are half-bridgeand full-bridge-modules. In both cases, the phase-legs consist of two IGBTs with antiparallel diodes. A large DC-capacitor is connected on the DC-side of the phase-leg(s), transferring electrical energy by DC voltage fluctuation. In addition, a mixture of different submodules is possible to reduce the number of IGBTs and as a consequence also the losses. This kind of setup is called a hybrid topology.

\section{B. Power Semiconductor Devices}

Inside the submodules of MMC, IGBTs are used as switching devices in half-bridge or full-bridge topology. Normally, IGBT modules are employed up to $2 \mathrm{GW}$ transfer power rating, and press pack IGBTs (PPIs) are utilized above $2 \mathrm{GW}$ as higher nominal current rating by larger housings. In this paper, press pack semiconductors, especially PPIs, are described the beneficial use in the highest reliability applications such as HVDC systems. These applications are a good example of how application demand influences semiconductor development activities.

The required freewheeling diodes (FWD) for these PPIs are either chip diodes, which can be located inside the PPI package or special soft-switching diodes in a separate pressure contact package. With a separated diode package, high nominal currents can be achieved for a given housing size, due to single-chip solutions. Further advantages of the external, pressure-contacted diodes are the scalability of size depending on the current load and the behavior in the event of a fault. In press pack diodes there will be a short circuit between the 


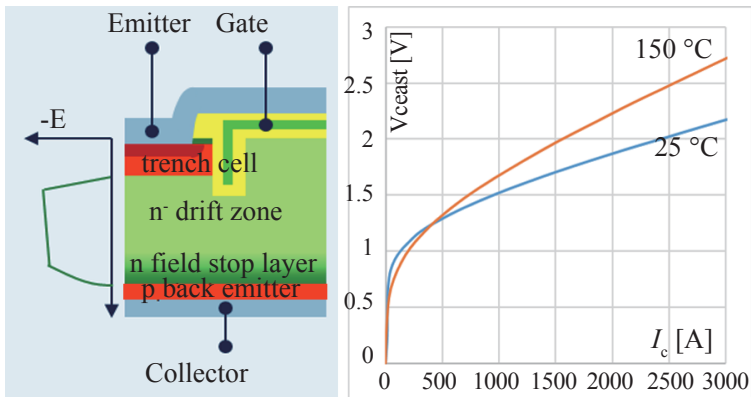

Fig. 1. The diagram of chip design (trench gate and field stop technology) and the typical output characteristic curve $\left(T_{\mathrm{j}}\right.$ is $25^{\circ} \mathrm{C}$ and $\left.150^{\circ} \mathrm{C}\right)$.

anode and the cathode during and after a fault. Modern external FWD are able to withstand turn-off power of $>10 \mathrm{MW}$ at turnoff $\mathrm{d} i / \mathrm{d} t>15 \mathrm{kA} / \mu \mathrm{s}$ at a full range of junction temperature. Furthermore, the surge current capability of these diodes is high enough ( $>80 \mathrm{kA}$ current for $10 \mathrm{~ms}$ half-sine wave) which means the protection thyristor is not needed anymore during a DC system fault. Another behavior (short-on-fail) contributes to an improved protection concept of the systems [3]-[4].

\section{NEW PPI}

The first product of PPI is a $4.5 \mathrm{kV} 3000$ A device with $125 \mathrm{~mm}$ pole piece diameter, which consists of 36 pcs of IGBT chip-stacks. The innovative design of chip-stack and housing technologies enables to create a perfect fitting portfolio with different current values and in addition with or without internal FWD to cover different applications and power ranges.

\section{A. IGBT Chip Technologies}

IGBT chip with a trench gate structure is designed to reduce the conduction losses with negligible influences on the tail current and turn-off losses. It has been proven as an effective solution to minimize the saturation voltage of IGBT chip. Another point, field stop technology is used to reduce the thickness of silicon for lower conduction resistance and higher blocking voltage, which also reduces the tail current and lowers the turn-off loss slightly. The IGBTs with trench gate and field stop technology have been in commercial production for many years already [5].

For this new PPI, the latest innovative $4.5 \mathrm{kV}$ trench IGBT chip technology is adopted. The same chip technology is also used in the latest IGBT module generation, for a long period successfully. Only slight mechanical modifications needed to be optimized for adapting the chip in press pack devices. One of the big improvements of the trench technology is of course the increase of maximum operating temperature from $125^{\circ} \mathrm{C}$ to $150{ }^{\circ} \mathrm{C}$. Besides this benefit, the conduction losses of the chips are decidedly reduced a lot compared to IGBT with planar technology. The typical on-state voltage is only $2.16 \mathrm{~V}$ at $25{ }^{\circ} \mathrm{C}$ junction temperature and $2.70 \mathrm{~V}$ at $150{ }^{\circ} \mathrm{C}$ junction temperature as shown in Fig. 1.

An IGBT to be used in an MMC circuit can be optimized for low switching frequency $(50-150 \mathrm{~Hz})$. Due to that and due to the technology curve of a silicon semiconductor the Vcesat can be optimized for a low value also. That reduces the whole converter losses. In addition to this the RBSOA is enlarged, which offers better robustness of the IGBT during turn-off in field application [6].

\section{B. Chip Stack by Low-Temperature Sintering (LTS)}

Due to the excellent thermal conductivity and electroconductibility, copper is the customary material for interconnection in high-power semiconductors. However, there is a mismatch in thermal expansion between silicon and copper, which would lead to severe stress and ultimately to device failure if copper and silicon are attached directly. This is why a layer of a better matching metal, usually molybdenum, shields the silicon from the stress generated by the mismatch of thermal expansion. There are several options to join silicon and molybdenum, such as free-floating, alloying, and sintering.

The free-floating (FF) assembly is the simplest configura-tion since the molybdenum is just put on both sides of the silicon and the contact is created by the outside force. This is easiest to manufacture but increases the thermal resistivity compared to the other alternatives. Alloying has better thermal performance but requires process temperatures of around $700{ }^{\circ} \mathrm{C}$. This leads to thermal stress inside the device and changes the device behavior due to heavy modification on the alloyed surface. Besides this, the high process temperature results in changes inside the silicon, which are not acceptable. For the sake of optimum device performance and reliability, silver sintering is recommended as the best solution, called LTS. Here a layer of silver powder is placed between silicon and molybdenum. Under high pressure and moderate temperatures $\left(200-300^{\circ} \mathrm{C}\right)$, the silver powder forms links between the silicon, the molybdenum, and each other, thereby creating a durable connection [7].

After attaching the silicon between two plates of molybdenum as a chip-stack, the IGBT chip is well protected from both thermal and mechanical stress. Due to the LTS process, the electrical data of this chip-stack are stable even under a wide range of pressure. Then the static and dynamic parameters can be measured at this early stage for every single chip-stack, e.g., VGEth, VCEsat, Eon, Eoff, etc. Chip-stacks with similar parameters are recommended for one group for PPI assembly, which would ensure the static and dynamic current sharing among the IGBTs or diodes in one housing. Each chip-stack is marked with an individual QR code on both surfaces to identify, thus full traceability of chip-stacks is possible as shown in Fig. 2.

Besides this benefit, the mechanical robustness of the chipstack, comparing with a bare die, is improved dramatically. Therefore, the handling in production is getting much easier and many negative influences are reduced to zero, e.g., particles. Even so, the production line is highly automated and aims to reduce variation in processing.

The LTS technology enables to reduce the number of the surface interface by $50 \%$ compared to free-floating, which 


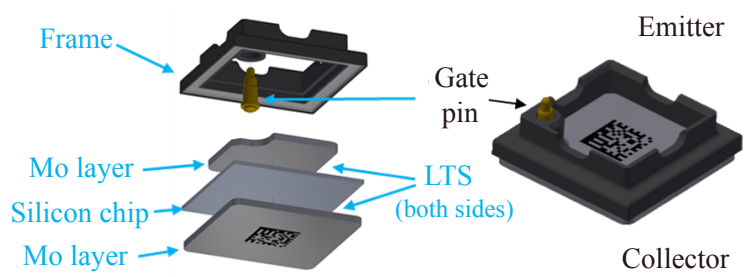

Fig. 2. Chip stack design incl. QR-code on both sides.

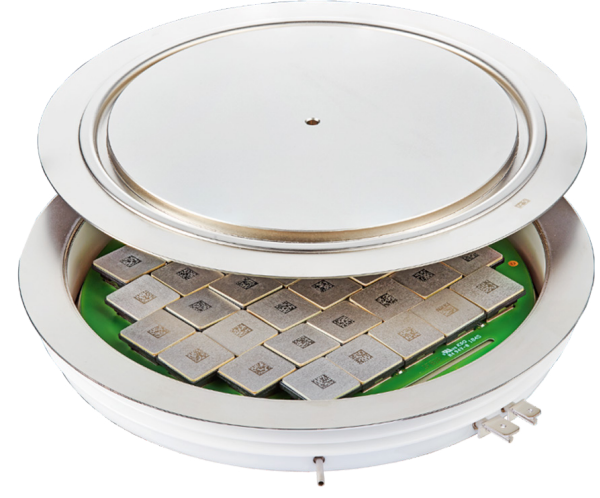

Fig. 3. Housing design of $4500 \mathrm{~V} / 3000 \mathrm{~A}$ PPI.

decreases the thermal resistance of each chip. This allows a higher power density of the chips and increases the current capability of the PPI. In addition to this, the risk of a surface problem is reduced because of fewer interfaces.

\section{Hermetic Housing}

A key factor for the production of a high reliablesemiconductor is also the interface from the chips to the outside e.g., the heatsink. Especially on a PPI, where several single chips have to be pressed homogeneously to perform best performance and reliability. Due to that, a lot of development and testing was done on a round shape ceramic disc housing as the best solution as shown in Fig. 3 .

This round-shaped ceramic housing is hermetically sealed and filled with nitrogen to ensure a stable gas atmosphere inside the capsule. Due to the inert behavior of nitrogen, this gas is already used in disc semiconductors as a standard for decades. By hermetically sealing, no environmental issue can harm the inside chips. A small amount of helium is added during the closing process. It aims to control the sealing process of the housing by a helium leakage test. Each device is tested to ensure a long lifetime due to the fixed nitrogen atmosphere inside the ceramic housing [8]-[9].

Inside the housing, a specially designed printed circuit board (PCB) is used to distribute the gate signal for all inside chips simultaneously. The impedance matching is mainly achieved by resistor networks from outside control terminals to each chip, including gate resistors and emitter resistors. Furthermore, the design was checked versus the capacitive or inductive interference of gate signals between locations of all

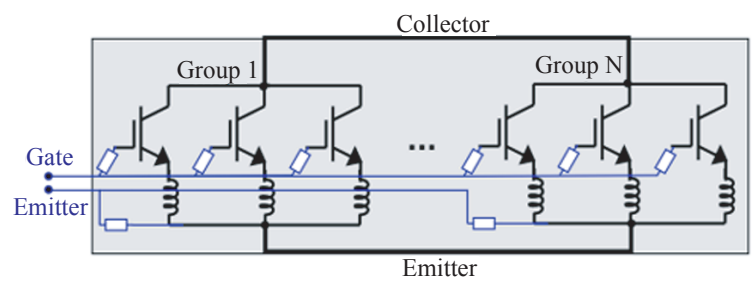

Fig. 4. Diagram of the gate control circuit of PPI.

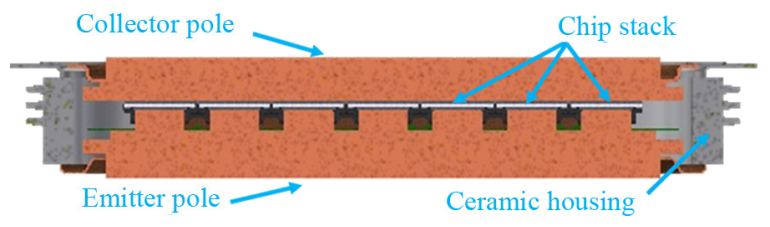

Fig. 5. Cross-section of the internal structure of PPI housing.

chips. It is necessary to ensure homogenous current sharing among all chips, both for the static and dynamic stages.

There are 36 chip stacks in parallel connection in the housing and divided into several groups. In the PCB board, each chip stack has a separated gate resistor and each group shares one emitter resistor. In this way, the gate signals are well controlled for each chip as shown in Fig. 4.

\section{Robust Structure and SCFM Feature}

For the new development of the PPI, the special requirements from VSC-HVDC applications have been considered. Here one failure scenario is a high discharge current from the low inductive connected capacitor. In order to fulfill this demand, the housing should withstand a high level of current pulse without an explosion. Here also the innovative housing design was enhanced for this case non-rupture behavior by different measures, e.g., ceramic design, welding process. Besides, since no silicone gel is needed to keep the bond wires in place and assure clearance and creepage, the case non-rupture current level is also improved as shown in Fig. 5.

A very important feature of the PPI is to ensure a longterm short on fail behavior in case of failure, which is called short circuit failure mode (SCFM). It means after the damage of only one chip, the PPI will stay in a short circuit mode stably for a long period, at least one year from a system maintenance request. It is impossible to realize this important feature by using springs to connect the chips in a high current application. The problem was solved by innovative measures of housing design in interaction with the chip-stack design and homogeneous pressure distribution. And beyond that, the losses of the failed device must be lower than on a "working" device to avoid an overheating of the PPI due to fixed cooling capability.

The SCFM was tested under different failure modes defined by the application. The first test scenario is that a full load current is applied to a damaged PPI. For this test one damaged chip is built into the housing while all other chips are not 


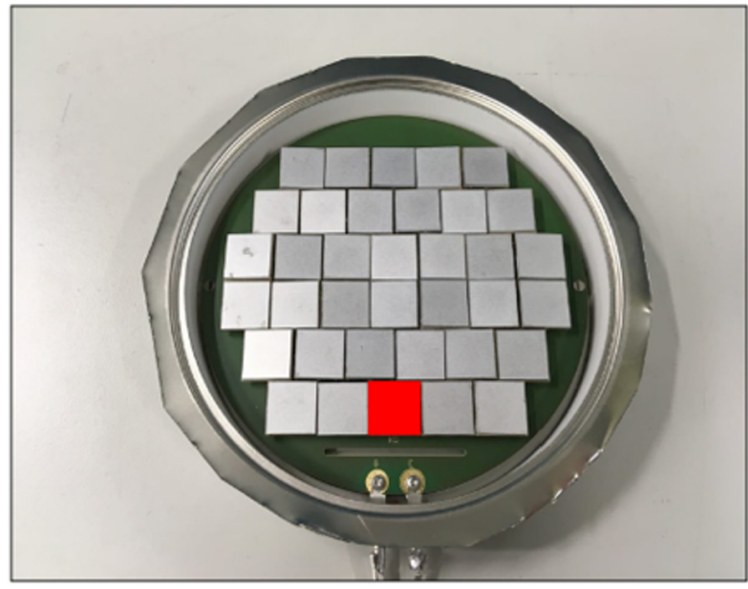

Fig. 6. Example for position of pre-damaged chip in the PPI housing.

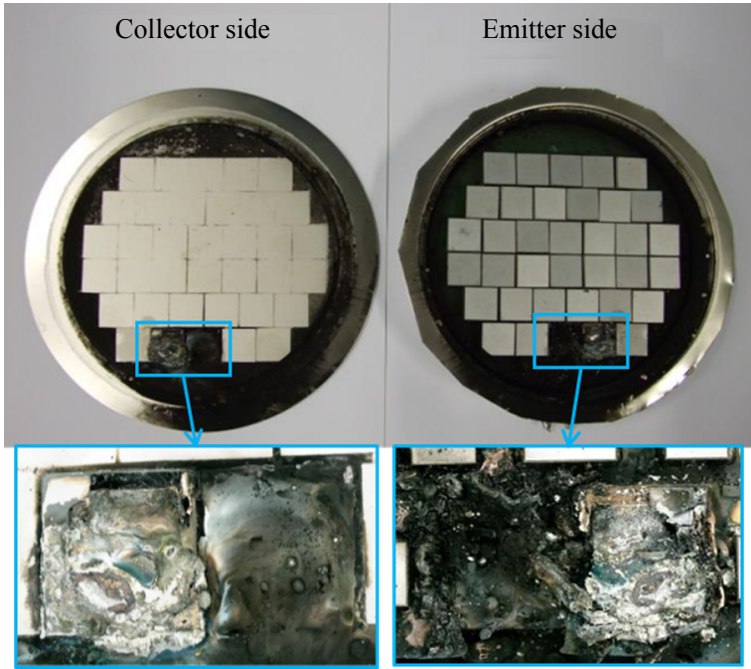

Fig. 7. The photo of molten full metal contact between collector and emitter inside of the tested device after $50 \mathrm{~h} / 3000 \mathrm{ADC}$ load testing.

damaged, to create the worst-case scenario. The housing is hermetically sealed and the device is built into a mechanical setup with double side cooling as in the application as shown in Fig. 6.

For the testing, a DC current of $3000 \mathrm{~A}$ is applied to the predamaged device and the voltage between collector and emitter is recorded. In one of the worst cases, the recorded voltage is fluctuating especially in restarting the DC current during the first $20 \mathrm{~h}$. After that period the voltage is stable on a lower level than on a non-damaged PPI. The test was stopped after $50 \mathrm{~h}$ because of no changes on voltage, then the tested devices are investigated deeply. After opening the housing of the tested devices, a molten full metal contact could be observed robustly, as shown in Fig. 7.

For the second test scenario, the full load current is applied to a damaged PPI, which is ruined by a high surge current generated by capacitor discharging. For this test, a pre-damaged device is built again as in the first test scenario and pressed in series with a thyristor in a mechanical setup also with double
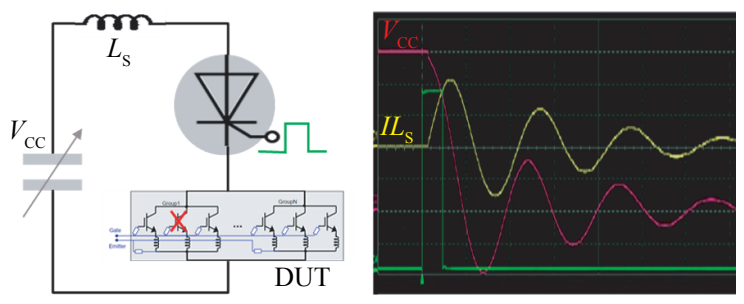

Fig. 8. The setup of the second test scenario at capacitor discharging and the typical waveform $\left(I_{L_{\mathrm{S}}}\right.$ : discharging current; $V_{\text {cc }}$ : capacitor voltage; Green: trigger signal).

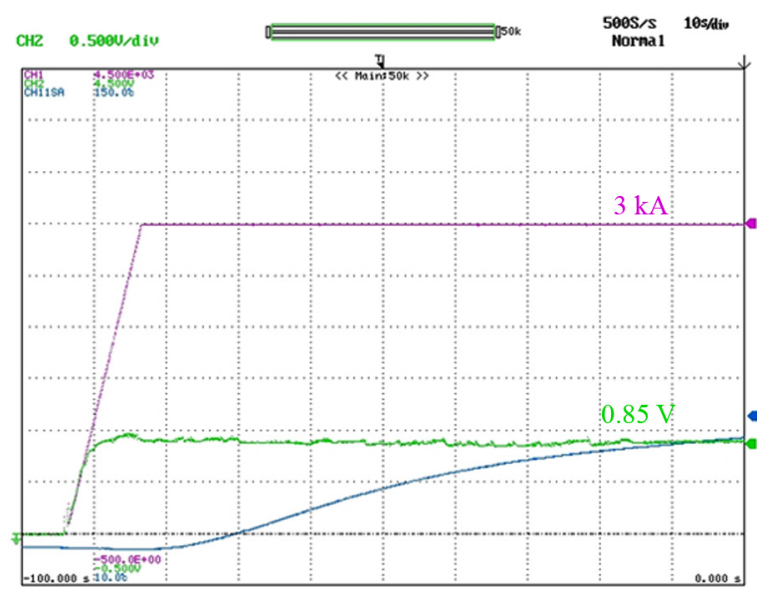

Fig. 9. Voltage monitoring of the failed device at 3000 A DC load test.

side cooling. The thyristor is needed to block the voltage during charging the capacitor. By triggering the thyristor, the current will flow through the pre-damaged PPI and the thyristor, shown in Fig. 8. Both devices will be destroyed electrically due to a huge discharging current, with a typical value of 500-1200 kA.

After the discharge, a DC current of $3000 \mathrm{~A}$ is applied and the voltage is monitored as at the first test scenario. In comparison to the first test scenario, the voltage at this test scenario is directly stable when the current is applied as shown in Fig. 9.

SCFM is a very important feature of a power device in a series connection topology and enables an uninterruptible operation even with few device failures. Thus, the system reliability is improved in field service, e.g., MMC for VSCHVDC. On the other hand, thanks to the hermetic housing and excellent performance of power cycling from the sintering process, it seems the only way to achieve a $30+$ years lifetime as expected for HVDC systems [10].

\section{E. Thermal Performance}

By the innovative design of the housing, a nearly symmetric double-side cooling (DSC) of the IGBT chips is possible. This means the thermal resistance of the chip to the collector is nearly the same as the chip to the emitter. It enables symmetric heat flow towards the heatsinks, which decreases the complexity of cooling management.

In general, the overall thermal performance of a device is limited by the temperature difference and distribution among 


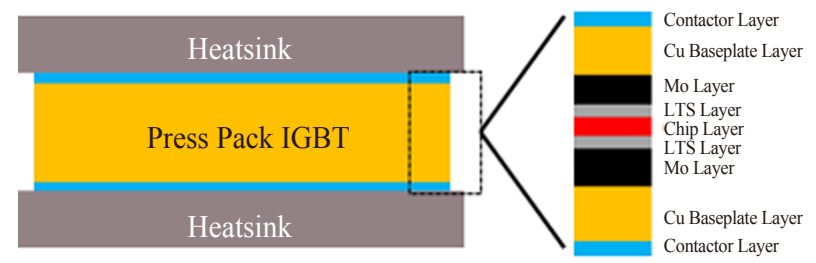

Fig. 10. Thermal simulation model of the PPI.

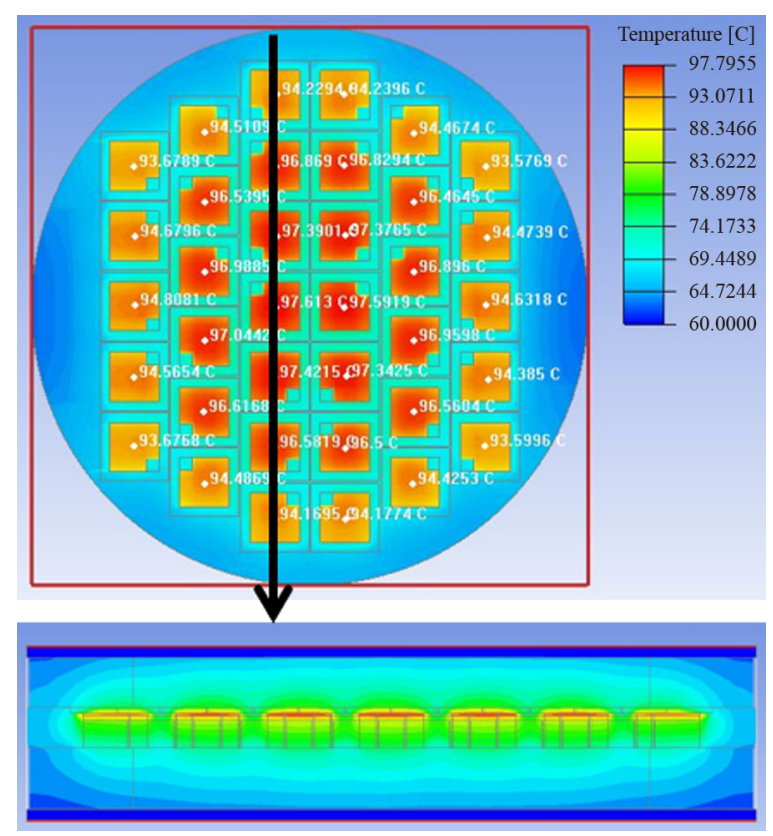

Fig. 11. Thermal simulation of chips temperature distribution and a crosssection for vertical thermal conduction.

the chips, especially for the PPI with so many chips in parallel inside. Benefited from the LTS and DSC technology as introduced before, it makes a great contribution to improving the internal thermal performance among all chips together with an optimized mechanical structure design.

A thermal simulation example based on the new $4.5 \mathrm{kV} / 3000 \mathrm{~A}$ PPI was carried out, the modeling setup is shown in Fig. 10. A detailed internal structure was built including the copper baseplates, the Mo layers, LTS layers, and silicon chip, as well as an external contact layer between PPI and the heatsink. The PPI is cooled by double side heatsink which is defined as a constant temperature of $60^{\circ} \mathrm{C}$.

According to the application requirements and the output characteristic of the PPI, the $V_{\text {CEsat }}$ value of the device is approx. $2.47 \mathrm{~V}$ under junction temperature $100{ }^{\circ} \mathrm{C}$ through a $3000 \mathrm{~A}$ current. The conduction power loss is calculated as $7416 \mathrm{~W}$ for the whole device (206 W per chip), which is thought of as the most critical situation in field application. The results are shown below in Fig. 11, the temperature difference between the hottest chip and the coldest one is approx. $4 \mathrm{~K}$ inside the PPI housing and the max junction temperature is approx. $97.8^{\circ} \mathrm{C}$, which is very low compared to the maximum allowed operating temperature of $150{ }^{\circ} \mathrm{C}$. When using a dedicated heatsink, with specially designed water channels for this round press pack device,

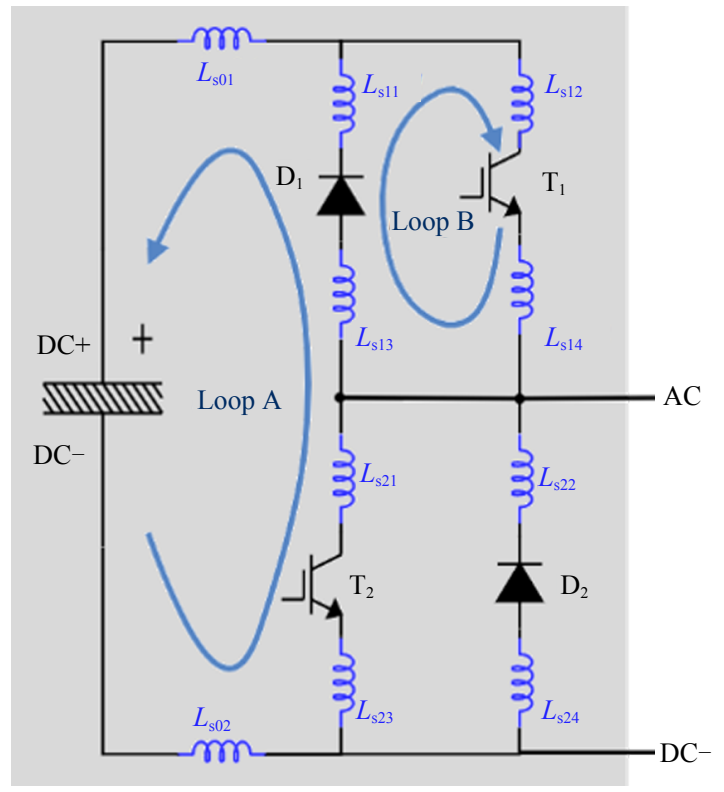

Fig. 12. The commutation loops of half-bridge stack using separate PPIs and FWDs.

the difference of junction temperature among all chips would be within $1 \mathrm{~K}$.

\section{STACK Design}

As the PPI and FWD are separated into two housings, the power stack consists of 2 PPIs and 2 FWDs for a halfbridge submodule, and 4 PPIs and 4 FWDs for a full-bridge submodule accordingly. Here the half-bridge is taken as an example to illustrate the mechanical design concept.

Designing such a stack with independent PPI and FWD, 4 devices are preferred to assemble into one stack which can also share mechanical accessories, e.g., frames, springs, heatsinks, busbar, etc. It is an advantage when the external FWD can be installed in the same mechanical setup as the PPI. This optimizes the space, weight and cost of the converter valve and simplifies mechanical construction [11].

In electrical design, two commutation paths should be noticed seriously for each PPI in switching, as shown in Fig. 12. Taking $T_{2}$ as an example, commutation loop $A$ is the paths of load current between DC-link and output terminal while $\mathrm{T}_{2}$ in effective switching, the stray inductance $L_{\mathrm{sA}}$ is:

$$
L_{\mathrm{sA}}=L_{\mathrm{s} 01}+L_{\mathrm{s} 11}+L_{\mathrm{s} 13}+L_{\mathrm{s} 21}+L_{\mathrm{s} 23}+L_{\mathrm{s} 02}
$$

This $L_{\mathrm{sA}}$ is a key factor influencing the voltage overshoot $\left(\Delta V_{\mathrm{CE}}\right)$ of collector-emitter during $\mathrm{T}_{2}$ turning off, and the current decreasing slope $\left(\mathrm{d} i_{\mathrm{c}} / \mathrm{d} t\right)$ is another factor as described in (2) below:

$$
\Delta V_{\mathrm{CE}}=L_{\mathrm{sA}} \times\left(-\mathrm{d} i_{\mathrm{c}} / \mathrm{d} t\right)+V_{\mathrm{FRM}}
$$

The $V_{\mathrm{FRM}}$ is the peak forward recovery voltage of the freewheel diode $\left(D_{1}\right)$. It is an inherent characteristic determined 

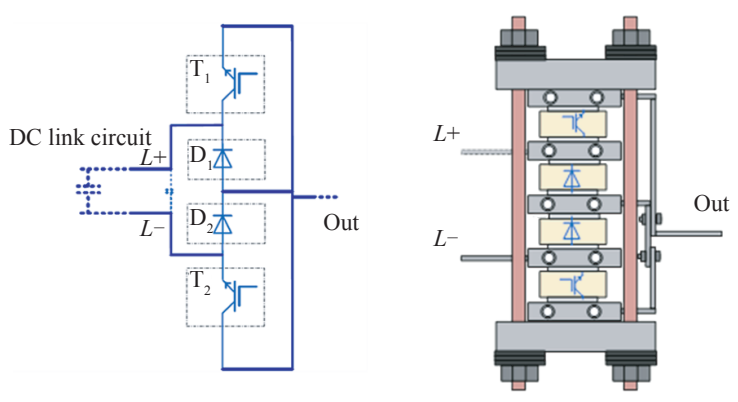

Fig. 13. A proposal of circuit diagram and mechanical design of the halfbridge stack for $4500 \mathrm{~V} / 3000 \mathrm{~A}$ PPI.

by chip design under certain conditions including junction temperature, load current value and its increased slope. Generally, it is negligible as only a small part of the whole spike during turning off, but it is more critical for clamping the negative voltage $\left(V_{\mathrm{EC}}\right)$ applying on the emitter-collector of $\mathrm{T}_{1}$. For example, in commutation loop B (between $\mathrm{T}_{1}$ and $\mathrm{D}_{1}$ ) during $\mathrm{D}_{1}$ forward recovery process, the stray inductance of loop B $\left(L_{\mathrm{sB}}\right)$ is:

$$
L_{\mathrm{sB}}=L_{\mathrm{s} 11}+L_{\mathrm{s} 12}+L_{\mathrm{s} 13}+L_{\mathrm{s} 14}
$$

While the negative voltage $V_{\mathrm{EC}}$ is:

$$
V_{\mathrm{EC}}=\left(L_{\mathrm{s} 11}+L_{\mathrm{s} 13}\right) \times \mathrm{d} i_{\mathrm{F}} / \mathrm{d} t+V_{\mathrm{FRM}}
$$

Here only partial stray inductance of $L_{\mathrm{sB}}$ is influencing the negative voltage, because the increasing $\mathrm{d} i_{\mathrm{F}} / \mathrm{d} t$ of $\mathrm{D}_{2}$ only flows through $L_{\mathrm{s} 11}$ and $L_{\mathrm{s} 13}$. Normally, the value of $L_{\mathrm{s} 11}$ and $L_{\mathrm{s} 13}$ are very small, thus the $V_{\mathrm{FRM}}$ is the main factor influencing on the negative voltage $\left(V_{\mathrm{EC}}\right)$. It is worth noting that IGBT chip only has a limited reverse blocking capability and may lead to failure if the peak value is over $200 \mathrm{~V}$.

There is a recommended half-bridge stack design which is straight towards field system solutions, it was checked and realized as a demonstrator of an MMC cell. The two FWDs are in the middle and two PPIs are in outside for better cooling. Five pieces of heatsinks are used for double side cooling and also as a conductive part connecting the external copper busbar. Here the standard shape and pole piece diameter is beneficial to find a broad portfolio of beside materials like a heatsink, bus bars etc. These designs can support the customers during their development phase to offer proven system solutions in a short period.

As illustrated in Fig. 13, the assembly sequence is $T_{1}, D_{1}$, $\mathrm{D}_{2}, \mathrm{~T}_{2}$ from top-down, the left side is DC-link connection from heatsink 2 and 4 , the right side is the output busbar connecting heatsink 1, 3, 5 together. In this stack design, the commutation loops for two PPIs are extremely symmetric, the stray inductance of loop A is approx. $100 \mathrm{nH}$ with a DC film capacitor and the stray inductance of loop B is approx. $30 \mathrm{nH}$. Such small stray inductance and symmetric layout are crucially important for the safety switching area (SOA) both for PPI and FWD.

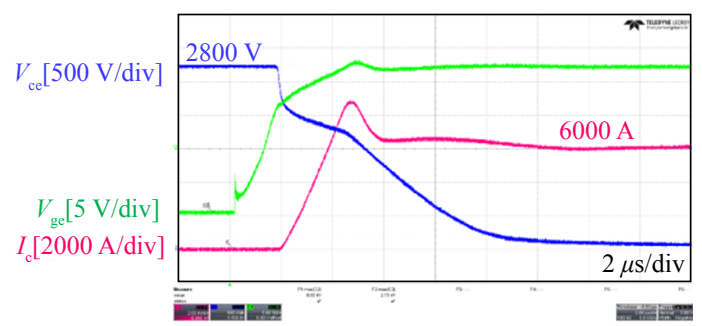

(a) Turning on

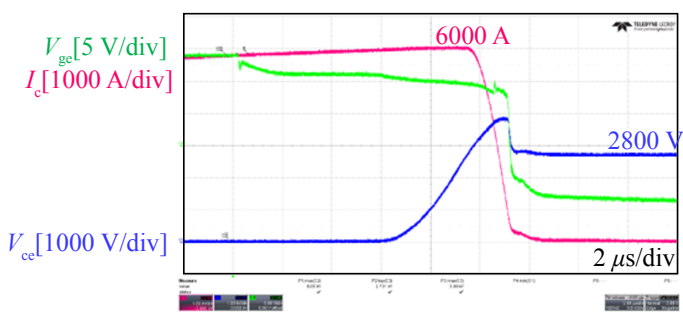

(b) Turning off

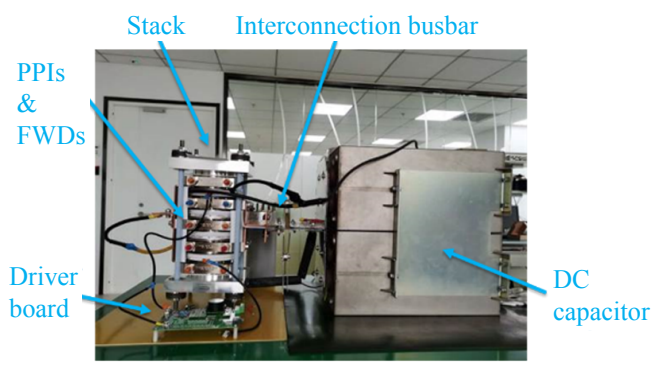

(c) PPI double pulse test setup

Fig. 14. The typical switching waveform of 4500 V/3000 A PPI.

Based on the demonstrator in the half-bridge stack, the switching test is performed in a double pulse test. The platform of the PPI switching test is under $2800 \mathrm{~V}$ DC link voltage with $6000 \mathrm{~A}$ load current, and the gate voltage is using $+15 \mathrm{~V} /-10 \mathrm{~V}$ with the default gate resister. After heating up the whole stack up to $150{ }^{\circ} \mathrm{C}$, the waveforms are measured as shown in Fig. 14, where the commutation loop is measured as approx. $100 \mathrm{nH}$ which fits for the real design in field application.

On the other hand, in mechanical verification, the pressure distribution should be also checked carefully for each device. A test setup is shown in Fig. 15, 8 pieces of Fuji prescale are installed between each pole piece of the 4 pieces of press pack device during the assembling. After that the force increased up to the nominal value ( $60 \mathrm{kN}$ for $125 \mathrm{~mm}$ device). On the Fuji prescale, a whole picture of pressure is shown as a different gradation of red color. The more intense the red color is the higher the intensity of pressure. The absolute value can be calculated by a software analysis tool, for the used prescale the highest value is approx. $10 \mathrm{MPa}$ and the lowest value is less than $2.5 \mathrm{MPa}$. The pressure distribution is strongly related to chip positions, where a hexagonal pattern is generated for the new PPI device accordingly.

It is the easiest way to check the final pressure distribution for each device with Fuji prescale. Nevertheless, the stacking process cannot be fully qualified with Fuji prescale, dynamic 

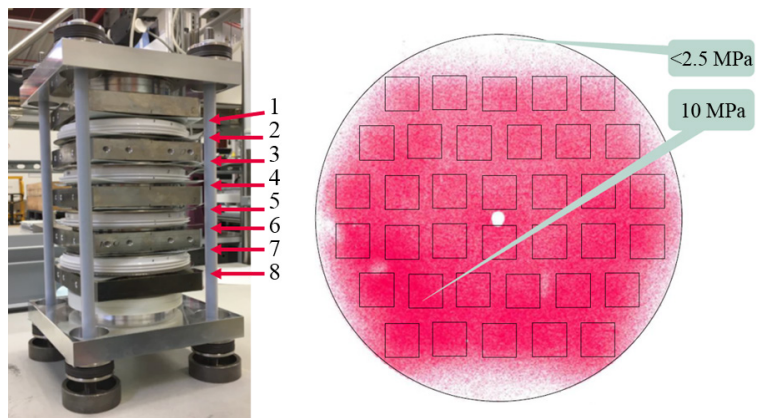

Fig. 15. The pressure verification test of the half-bridge demonstrator and the typical pressure print measured by Fuji prescale.

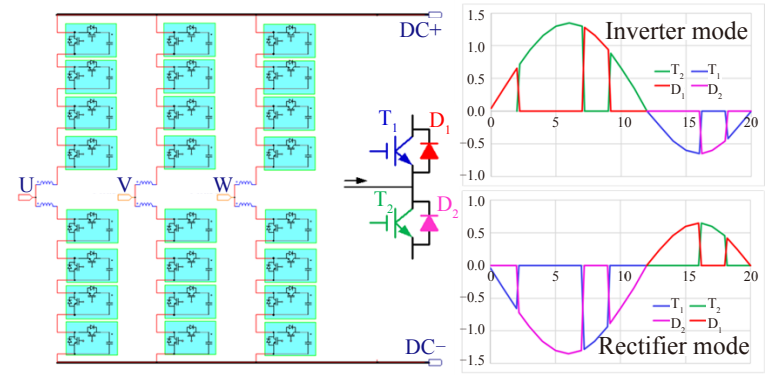

Fig. 16. MMC topology and the asymmetric load current in sub-module.

pressure changes are also important during the mounting process. A good mechanical design is the core technology in the application of a press pack device.

\section{SYSTEM APPLICATION}

In a large-scale VSC-HVDC system, there are thousands of submodules in series to compose a converter valve. Assuming the DC current splits into three equal branches and AC current splits two equal parts, the ideal valve current can be expressed by (5).

$$
i_{\mathrm{v}}(\omega t)=I_{\mathrm{DC}} / 3+I_{\mathrm{AC}} \times \sin (\omega t+\varphi) / 2
$$

$i_{\mathrm{v}}(\omega t)$ : Valve current;

$I_{\mathrm{DC}}$ : Transmission line DC current ;

$I_{\mathrm{AC}}:$ Peak value of phase current;

$\omega$ : The angular velocity of grid;

$\varphi$ : The phase angle between voltage and current.

There is a DC component $\left(I_{\mathrm{DC}} / 3\right)$ flowing through all submodules and causing unbalance load current for the upper side device and low side device, which is different from the conventional 2-level half-bridge as shown in Fig. 16 [12].

Meanwhile, the power loss distribution in the submodule is significantly different between rectifier mode operation and inverter mode operation. The bottom devices $\mathrm{T}_{2}$ and $\mathrm{D}_{2}$ are operating with high duty-cycle in the inverter and rectifier side respectively, thus generating significantly higher power losses. The power losses of each power device are simulated in two operation modes based on an example of a $\pm 800 \mathrm{kV} / 5 \mathrm{GW}$ project. The corresponding results are shown in Fig. 17.

In the simulation results, $\mathrm{T}_{2}$ takes the highest losses (normalized to $100 \%$ ) and the conduction power loss takes

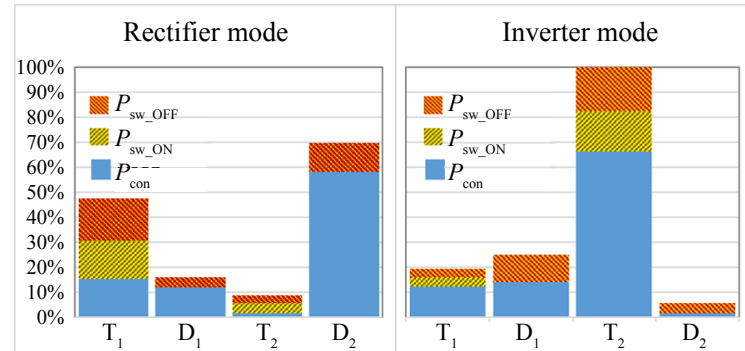

Fig. 17. The normalized power losses of each device during in rectifier operation mode and inverter operation mode (Simulation conditions: $\pm 800 \mathrm{kV} / 5 \mathrm{GW}$ converter, PPI $=$ P3000 and FWD $=$ D4600, Liquid cooling with $T_{\text {inlet }}=45^{\circ} \mathrm{C}$, $f_{\mathrm{sw}}=100 \mathrm{~Hz}, V_{\mathrm{dc}}=2200 \mathrm{~V},+5 \%$ cells for redundancy).

over $65 \%$ of its whole losses. It is also got the highest junction temperature comparing to other devices. While in the rectifier operation mode, the $\mathrm{D}_{2}$ gets the highest losses (about 69\%) and the conduction power loss takes over $84 \%$ of its whole losses. Thus, the conduction losses are confirmed as the main component of whole losses from the power device, and the newly designed low on-state voltage PPI could improve the system efficiency for an MMC converter.

Except for the conduction and switching losses from IGBT and diode, additional losses of the semiconductor e.g., blocking losses from both IGBT and diode chips has to be considered also, especially in standby mode. The blocking losses are generated by the leakage current of chips, which is strongly related to the junction temperature. Housing conduction losses are generated by the parasitic resistance of the package, which is not negligible in high power rating applications and should be included in the calculation of valve losses as well [13].

\section{OUTLOOK}

Due to the excellent performance and decreasing cost of VSC-HVDC system, it is under discussion to replace the LCCHVDC system for energy transmission in near future, especially for the inverter side. It requires a higher current rating PPI in such high-power stations, e.g., $\pm 800 \mathrm{kV} / 8 \mathrm{GW}$ station. A 5000 A PPI is already proposed for the next generation VSC-HVDC system for long-distance power transmission in China. The new device could be scaled up from the existing chip-stacks easily with new 6-inch housing. DC networks with many HVDC stations are also under discussion. For these networks, voltagesource converters will be used in particular. Various topologies will be taken into account here, which will continue to require high reliable press pack semiconductors in the future, as described in this paper.

Besides the power semiconductors, the question for the protection of MMC cells is also getting more and more attention. Today's solution, with a mechanical bypass switch using springs to store the energy for the closing process, to shortcut an MMC cell in case of failure, is a robust but very slow and non-reliable solution. As the closing time of these mechanical switches is quite long, various from 3-10 ms due to design, there is no protection for the MMC cell because of the fast-current discharge of 100-150 $\mu$ s. Additionally, the mechanical moving 
parts cannot ensure a reliable closing process after a long time of non-movement, when springs are used. Full protection can be offered by specially designed semiconductors to replace these mechanical switches. The advantages of these switches are given, by no moving parts, fast response time $\leqslant 10 \mu \mathrm{s}$, and compact mechanical design. This kind of semiconductor is already under development, but due to the complexity of the protection scenarios, a lot of testing still needs to be done, to ensure a quite wide range of protection.

\section{CONCLUSION}

As introduced in this paper, the development of the new PPI is strictly in accordance with the market demand for a highly efficient and high reliable device for HVDC and other applications with low switching frequency like FACTS, DCbreaker. This new device is using the latest trench IGBT chip technology to reduce conduction and switching losses. Due to the enhanced mechanical design, e.g., LTS technology, it can ensure a long time short on fail behavior in case of failure. Hermetically sealed housing is a significant advantage to improve the reliability and lifetime of power devices in field service. With an external FWD, it helps to realize a cost-effective half-bridge stack by selecting different current rating devices in a sub-module design based on system requirements. Based on the current design concept, a higher power sub-module is practicable with the developing new press pack device.

\section{REFERENCES}

[1] J. Gerdes, "Siemens debuts HVDC plus with San Francisco's trans bay cable," in Living Energy, Issue 5, Jul. 2011.

[2] R. Marquardt, "Modular multilevel converter, impact on future applications and semiconductors," in ETG Fachtagung Bauelemente der Leistungselektronik, Bad Nauheim, 2017.

[3] R. Barthelmess, M. Beuermann, and N. Winter, "New diodes with pressure contact for hard-switched high power converters," in Proceedings of the EPE'99, Lausanne, Switzerland, 1999.

[4] M. Schenk, J. Przybilla, U. Kellner-Werdehausen, R. Barthelmess, J. Dorn, G. Sachs, M. Uder, and S. Völkel, "State of the art of bipolar semiconductors for very high power applications," in Proceedings of PCIM Europe 2015, Nuremberg, Germany, pp. 930-936.

[5] J. G. Bauer, F. Auerbach, A. Porst, R. Roth, H. Ruething, and O. Schilling, "6.5 kV-modules using IGBTs with field stop technology," in Proceedings of the 13th International Symposium on Power Semiconductor Devices \& ICs. IPSD'01 (IEEE Cat. No.01CH37216), Osaka, Japan, 2001, pp. $121-124$.

[6] J. Lutz, H. Schlangenotto, U. Scheuermann, and R. De Doncker, Semiconductor Power Devices, Berlin, Germany: Springer-Verlag Berlin Heidelberg, 2011, pp 327-340.

[7] H.Schwarzbauer and R.Kuhnert, "Novel large area joining technique for improved power device performance," in IEEE Transactions on Industry Applications, vol. 27, no. 1, pp. 93-95, Jan.-Feb. 1991.

[8] A. Gurvich, O. Schilling, J. De Bock, A. Rossin, and S. Mangesh, "Introduction of hydrogen sulfide (H2S)-protected IGBT modules," in PCIM Europe 2020, Germany, 2020, pp. 1-6.

[9] C. Zorn and N. Kaminski, "Acceleration of temperature humidity bias (THB) testing on IGBT modules by high bias levels," in 2015 IEEE 27th International Symposium on Power Semiconductor Devices \& IC's (ISPSD), Hong Kong, 2015, pp. 385-388.

[10] T. Kobayashi, S. Fujioka, and H. Nakamoto, "Operation experiences and replacement planning of Shin-Shinano frequency converter No.1," in CIGRE Paper 324, CIGRE Symposium, Osaka, Japan, Nov. 2007.

[11] Paolo Bordignon, Haitao Zhang, Wei Shi, Nicola Serbia, and Alberto Coffetti, "HV submodules technology based on press pack IGBT for largest scale VSC-HVDC application," in 12th IET International Conference on AC and DC Power Transmission (ACDC 2016), 2016, pp. $1-6$.

[12] H. Wang and K. Ma, "IGBT technology for future high-power VSCHVDC applications," in 12th IET International Conference on AC and DC Power Transmission (ACDC 2016), Beijing, 2016, pp. 1-6.

[13] H. Wang, J. Przybilla, H. Zhang, and J. Schiele, "The new high reliable press pack IGBT for modular multilevel converter in VSC-HVDC applications," in 2020 4th International Conference on HVDC (HVDC), Xi'an, China, 2020, pp.14-19.

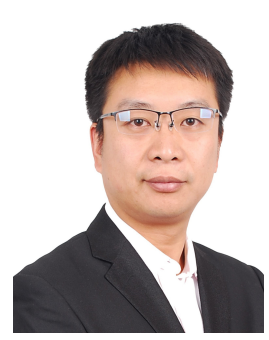

Heng Wang received the B.S. degree in electronic and information engineering from Xidian University, Xi' an, China, in 2007, and the M.S. degree in electrical engineering from Beijing Jiaotong University, Beijing, China, in 2016.

Currently, he is the Principal Engineer in Infineon, and responsible for field application of power semiconductors in greater China.

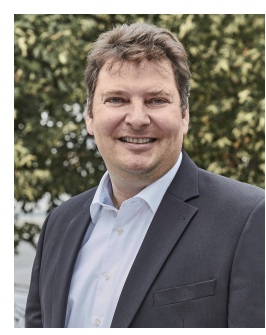

Jens Przybilla received the diploma degree in electrical engineering from the University of Paderborn, Germany, in 1996.

Currently, he is working as Senior Manager Technical Marketing for high power bipolar disc devices, including press pack IGBTs, at Infineon Technologies Bipolar GmbH \& Co. KG. Within Infineon he is Lead Principal Engineer for power transmission and distribution. He is holding several patents and published several papers regarding Thyristors and Diodes and their use in different applications.

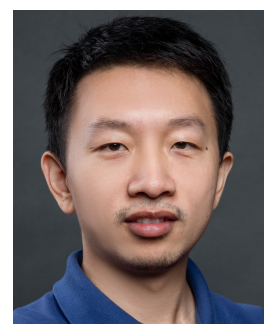

Hao Zhang received the B.S. degree in electrical engineering and automation in 2010, and M.S. degree in power electronics and power transmission in 2013 both from Nanjing University of Aeronautics and Astronautics, Nanjing, China.

Currently, he is the staff engineer in Infineon, and responsible for field application of power semiconductors in greater China.

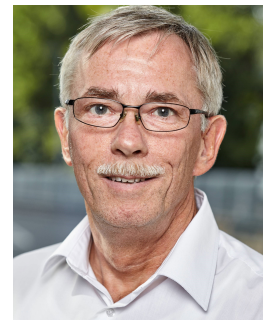

Juergen Schiele has an education in electrical engineering specialisation computer technology and energy technology from the Technical Centre DAG in Würzburg. He has gained more than 45 years of experience in $\mathrm{R} \& \mathrm{D}$ of power electronics working for Garbe Lahmeyer/GL Converter Technology in Aachen, Lloyd Dynamo Werke BU Drive Systems in Berlin, Infineon Technologies in Berlin, Warstein and Beijing, AEG Power Solutions in Warstein and Infineon Technologies Bipolar GmbH \& Co. KG in Warstein. In his various positions as R \& D Project Manager, R \& D Manager and Operations Manager Jürgen has worked in technologies like electrical drives, frequency converters, power converters, IGBT power modules, power electronics for renewables, UPS systems and power supplies. Within Infineon, he is Lead Principal Engineer for drives and power electronic converter stacks. 